Erratum

\title{
Erratum to: Soft Tissue Phantoms for Realistic Needle Insertion: A Comparative Study
}

Alexander Leibinger, ${ }^{1}$ Antonio E. Forte, ${ }^{1}$ Zhengchu Tan, ${ }^{1}$ Matthew J. Oldfield, ${ }^{1}$ Frank Beyrau, ${ }^{2}$ Daniele Dini, ${ }^{1}$ and Ferdinando Rodriguez y Baena ${ }^{1}$

${ }^{1}$ Department of Mechanical Engineering, Imperial College London, Exhibition Road, South Kensington, London SW7 2AZ,

UK; and ${ }^{2}$ Lehrstuhl für Technische Thermodynamik, Otto-von-Guericke-Universität Magdeburg, Magdeburg, Germany

\section{Erratum to: Annals of Biomedical Engineering}

DOI 10.1007/s10439-015-1523-0

Reference 4 should be changed to:

Forte, A. E., S. Galvan, F. Manieri, F. Rodriguez y Baena, and D. Dini. A composite hydrogel for brain tissue phantoms. Mater. Des. 227:238-112, 2016.

Address correspondence to Ferdinando Rodriguez y Baena, Department of Mechanical Engineering, Imperial College London, Exhibition Road, South Kensington, London SW7 2AZ, UK. Electronic mail: f.rodriguez@imperial.ac.uk

The online version of the original article can be found under doi: 10.1007/s10439-015-1523-0. 